\title{
Domestic Violence Against Women: A Complex Issue in Pakistan
}

\author{
Rukhshanda Zarar* \\ Social Work Department, Sardar Bahadur Khan Women's University, Pakistan \\ *Corresponding author: Rukhshanda Zarar, Lecturer in Social Work Department, Sardar Bahadur Khan Women's University, Quetta, Pakistan
}

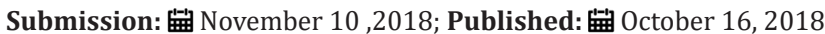

\begin{abstract}
Domestic Violence against women is widespread and complex issue in Pakistan. Nearly every woman practices domestic violence in her whole life. The aim of this paper is to aware, educate and inform the worse situation of domestic violence against women in Pakistan. This does not exist only in lower and middle class, but highly educated women also suffer because of male dominant society. It might be physical, sexual, or psychological violence. Our Pakistani culture, tradition, norms and values support this act. This is deeply believed in our society that women are inferior to men. This article focuses the worse situation of domestic violence against women in Pakistan.
\end{abstract}

Keywords: Domestic violence; Inequality; Male dominant Society; Equity

\section{Introduction}

Gender Based Violence is a universal reality of all societies regardless of income, class and culture. It would be difficult to find one woman, whom at one time or the other in her lifetime had not been afraid merely because of her sex. Women are discriminated based on race, language, ethnic group, culture, age or in the name of religion. GBV affects both the physical and emotional integrity of women and has devastating consequences not only for victims but for society. (Customary Practices Leading to Gender- Based Violence, Aurat Foundation [1], Gender Equity Program December 2012. The United States Department of Justice defines domestic violence as a pattern of abusive behavior in any relationship that is used by one partner to gain or maintain power and control over another intimate partner [2].

Violence against women shall be understood to encompass, but not be limited to, the following:

A. Physical, sexual and psychological violence occurring in the family, including battering, sexual abuse of female children in the household, dowry related violence, marital rape, female genital mutilation and other traditional practices harmful to women, nonspousal violence and violence related to exploitation;

B. Physical, sexual and psychological violence occurring within the general community, including rape, sexual abuse, sexual harassment and intimidation at work, in educational institutions and elsewhere, trafficking in women and forced prostitution;

C. Physical, sexual and psychological violence perpetrated or condoned by the state, wherever it occurs [3]
Domestic violence is strongly and directly related to inequality between men and women. But the contested legitimacy of gender equality impedes or complicates efforts to deal with domestic violence as a social problem in many parts of the world. There is strong and pervasive opposition to the notion that men and women should be equal in the context of the family. The corollary is the belief that domestic relationships are legitimately (i e., naturally and/ or divinely) hierarchical. In Muslim societies, this belief is both derived from and reinforced by shari'a, which tends to be interpreted to give men power over women family members. Thus gender inequality is acknowledged and justified in religious terms on the ground that God made men and women "essentially" different; that these differences contribute to different familial roles, rights and duties, which are complimentarily is crucial to the cohesion and stability of the family and society [4].

In 48 population-based studies from different parts of the world, ten to sixty nine percent (10-69) of the women reported having been physically assaulted by an intimate partner during their life time. A woman is battered, usually by her intimate partner; every 15 seconds and more than three women are murdered by their intimate partners every day in the United States. Domestic violence exists in both societies whether it is developing or developed. It is common concept that women in developed and advanced countries are enjoying their lives and liberty, but it is not true the truth is that every woman practice this experience in her life it can be less or more according to her situation, even women do not protest against these tortures and violence. God created man and woman equally 
nobody can claim that woman is inferior to man but unfortunately when we talk about particularly Pakistani society a woman considered only a subordinate, so she deserves maltreatment from males and society. She has to bear violence and torture from family and outside and no one can challenge and change this ill behavior. A woman performs her role as a mother, sister, daughter and wife in a well manner but despite this she faces different kind of physical violence and mental torture and when she wants to raise her voice against these acts then she is threatened for divorce.

Pakistan is one of such countries where domestic violence is common because of patriarchal feudal and tribal system. In this family system women have no value and status. They are considered inferior to men even they do not aware about their rights and utilization. Mostly women deprived of their rights for instance right of education, right of decision making in family matters, right of marriage and rights about their children. The basic reasons of domestic violence lack of education and unawareness, male dominant society and low socio-economic status of women in Pakistan, they are compelled to bear torture and violence. If any woman tries to raise voice for her rights then she has to face physical, mental and sexual violence and torture so nobody wants to take this risky step.

Domestic Violence is very common in Pakistani society if we study different reports and surveys then we aware that it is increasing day by day. These are reported cases which are visible but mostly women they don't report it because of their family pressure and cultural values and threaten from their husbands. When these victims' women do not have any choice then they attempt suicide and these cases are highly reported in USAID report of domestic violence against women and girls.

According to the USAID report (2010), 1,988, or a quarter of all reported cases of gender based violence in 2009, were murders or honor killings. While only 50 cases of stove burning were reported, a decrease of 18 percent from the previous year, acid throwing had increased substantially. Abduction and kidnapping were the second highest reported incidence of gender-based violence, with, 1,987 cases. Reports of rape and gang rape increased by 19 percent and numbered 928 cases. Suicide also reached a new high with 683 cases reported, an increase of 14 percent. Under reporting is a serious problem, particularly for crimes such as domestic violence, of which only 281 cases were reported. The dearth of data is also indicated in the 1,977 cases clubbed as "miscellaneous", including vani, swara, custodial violence, torture, trafficking, child marriages, incest, threat of violence, sexual harassment and attempted murder $[5]$.

Similarly, 7516 is the total number of reported cases of violence against women (VAW) from four provinces as well as FATA and Islamabad Capital territory (ICT) between January to December 2012. From these incidents, nearly $63 \%$ cases were reported from Punjab. Sindh had the second highest instance of reported VAW cases with a total 1628 cases which form $22 \%$ of the total reported cases. 674 cases were reported from Khyber Pakhtunkhwa (KP) and FATA. Islamabad was noted for 281 cases of VAW, which is a very high number compared to the size of the region which is much smaller and dwells a small ratio of population as opposed to the other regions. Baluchistan had a total of 167 reported cases. Murder, kidnapping, rape/gang rape, honour Killing and suicide were the highest among offences reported against women in 2012. A total of 1745 murders, 1607 cases of abduction, 1134 miscellaneous forms of the VAW,989 cases of domestic violence, 822 cases of rape/gang rape, 575 incidents of suicide and 432 cases of 'honour killing' were reported [6].

In Pakistan, there are cultural institutions, beliefs and practices that undermine women's autonomy and contribute to gender-based violence. Marriage practices can disadvantage women, especially when customs such as dowry and bride's price, Watta Satta and marriage to the Quran (a custom in Sindh where girls remain unmarried like nuns to retain family property in the family) exist. In recent years dowry has become the expected part of marriage. This increasing demand for dowry, both before and after marriage, can escalate into harassment, physical violence and emotional abuse. In extreme cases homicide or "stove-burns" and suicides can provide husbands an opportunity to pursue another marriage and consequently more dowry [7]. In many cases when a Pakistani woman is killed or injured by a family member, authorities refuse to investigate or prosecute the offender. In other cases, violence is excused as a legitimate response to "grave and sudden provocation." For Example, in a case in which a man was tried for killing his daughter and a young man whom he found in a "compromising state," the Lahore high court found that his actions were justified because his victims were engaging in immoral behavior that could not be tolerated in an Islamic state such as Pakistan [8].

Women face different kind of violence for instance physical, psychological, sexual abuse, mental torture but sometimes they do not identify that it is violence and how to deal with it. Man is considered superior authority so he has to right to threat and beat his woman. No one can interfere in this situation because this matter is considered personal and family. Our social system and culture favor this situation even police does not interfere in this matter that partners will solve this issue at home. Violence against women is not only a manifestation of sex inequality, but also serves to maintain this unequal balance of power. In some cases, perpetrators consciously use violence as a mechanism for subordination. For example, violence by intimate partners is often used to demonstrate and enforce a man's position as head of the household or relationship. For other forms of violence, the subordination of women might not to be the explicit motivation of the perpetrator but is nevertheless a consequence of his actions. For example, a man who rapes a woman whom he judges to be sexually provocative might justify his act as being an appropriate punishment for her transgression of socially determined rules of female behavior. Women themselves frequently do not challenge accepted norms of female behavior because of the fear of being attacked or raped. Thus, women's unequal status helps to create their vulnerability to violence, which in turn fuels the violence perpetrated against them [9]. 
This is observed that many laws are made time to time in Pakistan, but they don't fully support for a woman to take her right if she has no evidence for rape or gang rape accused then he will be free of charge and he will be ready for next crime with daring and courage. So, there is strongly need to implement these laws so that a common woman can access easily. Zia-ul-Haq introduced the Hudood Ordinances, which changed the laws on rape and adultery and made fornication a crime, and the law of evidence, which renders the evidence of women equal to only half that of a man in some cases [10]. It seems from the available data that these laws are still used to control and punish women. The Hudood Ordinance was criticized severely at different forums as it was found that in cases if a woman could not prove rape or gang rape, she was accused of adultery and confined.

Several complex and interconnected institutionalized social and cultural factors have kept women particularly vulnerable to the violence directed at them, all of them manifestations of historically unequal power relations between men and women. Factors contributing to these unequal power relations include: socioeconomic forces, the family institutions where power relations are enforced, fear of and control over female sexuality, belief in the inherent superiority of males, and legislation and cultural sanctions that have traditionally denied women and children an independent legal and social status [11]. Pakistani culture and male dominant society cannot bear the liberty and rights of woman. Woman is considered a vulnerable and defenseless object that has no right to live with freedom and comfort. She must accept superiority of males because these are our cultural and traditional values and if any one reject from these norms and values then she has to prepare for punishment and physical, mental torture and violence.

\section{Conclusion}

The facts and figures about domestic violence against women in Pakistan indicate the real picture that domestic violence is increasing day by day. Many factors support violence against women in Pakistani society for instance male dominant society, women social economical condition, cultural and family system and unawareness of women about their rights and lack of legal protection [12]. There is need to make policies and laws to remove violence against women and these should be implementable and common woman should be access. There is need to aware and educate women regarding their rights and raise voice against violence. Government and Non-Governmental Organization should participate against this illegal act.

\section{References}

1. Aurat Foundation (2012) Customary practices leading to gender - based violence, gender equity program.

2. The United states Department of Justice (2017) What is domestic violence.

3. Banerjee S (2009) Violence against women in global asia published in india by Swastik publications. pp. 1-2.

4. Hajjar L (2004) Religion, State power, and domestic violence in Muslim Societies: A framework for comparative analysis published by American bar foundation.

5. USAID (2011) Gender based violence in Pakistan: A scoping Study.

6. http:/www.justice.gov/OVW/domestic-Violence.

7. Niaz U (2004) Women's mental Health in Pakistan. World Psychiatry $3(1): 60-62$.

8. Human Rights Watch (1999) Crime or Custom? Violence against Women in Pakistan. New York, USA, p. 42.

9. Watts C, Zimmerman C (2002) Violence against women: Global scope and magnitude. Lancet 359(9313): 1232-1237.

10. Mehdi R (1990) The offense of Rape in the Islamic Law of Pakistan. International Journal of the Sociology of Law

11. Unicef (2000) Domestic violence against women and girls.

12. Ali PA, Gavino MIB (2008) Violence against women in Pakistan: A framework for analysis.
Creative Commons Attribution 4.0

International License

For possible submissions Click Here
Submit Article

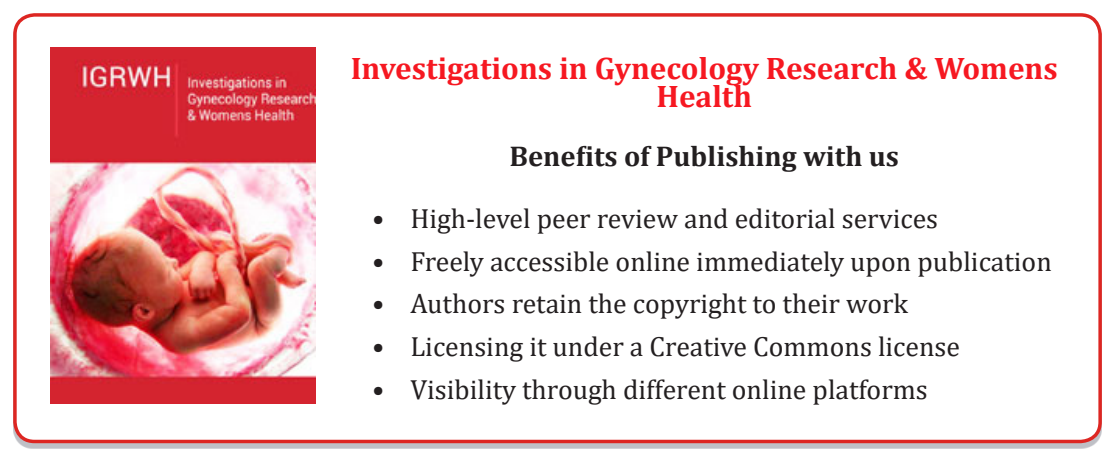

